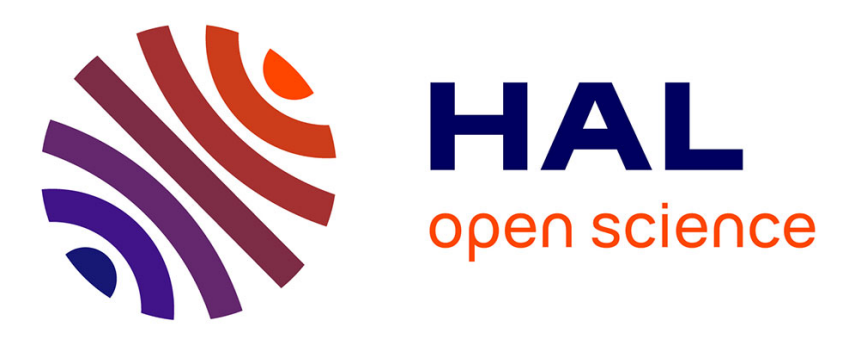

\title{
Vibration Reduction Control of Switched Reluctance Machine
}

Man Zhang, Imen Bahri, Xavier Mininger, Cristina Vlad, Éric Berthelot

\section{To cite this version:}

Man Zhang, Imen Bahri, Xavier Mininger, Cristina Vlad, Éric Berthelot. Vibration Reduction Control of Switched Reluctance Machine. IEEE Transactions on Energy Conversion, 2019, 34 (3), pp.1380 1390. 10.1109/TEC.2019.2908458 . hal-02109992

\section{HAL Id: hal-02109992 \\ https://hal.science/hal-02109992}

Submitted on 11 Mar 2020

HAL is a multi-disciplinary open access archive for the deposit and dissemination of scientific research documents, whether they are published or not. The documents may come from teaching and research institutions in France or abroad, or from public or private research centers.
L'archive ouverte pluridisciplinaire HAL, est destinée au dépôt et à la diffusion de documents scientifiques de niveau recherche, publiés ou non, émanant des établissements d'enseignement et de recherche français ou étrangers, des laboratoires publics ou privés. 


\title{
Vibration Reduction Control of Switched Reluctance Machine
}

\author{
Man Zhang, Imen Bahri, Xavier Mininger, Cristina Vlad and Eric Berthelot
}

\begin{abstract}
In this paper, a new vibration reduction control of the switched reluctance machine (SRM) is proposed that takes into consideration the undesirable effects of the torque ripple. The control approach aims to reduce the variation of the sum of radial forces while optimizing the control parameters of the machine to achieve the torque ripple minimization. Thus, a reference current adapter is used in order to handle the trade-off between the vibration reduction and the torque ripple reduction. It produces an auto-tuning reference current that limits the variation of the torque and of the total radial force. The effectiveness of the proposed control strategy is proved by simulation and experimental results. Comparisons with conventional control methods investigating vibrations, noise and torque ripple are provided, which show the advantages of the control approach based on an auto-tuning reference current.
\end{abstract}

Index Terms-Auto-tuning reference current, direct force control, radial force, switched reluctance machine (SRM), vibration reduction

\section{INTRODUCTION}

$\mathrm{S}_{\mathrm{s}}^{\mathrm{w}}$ WITCHED reluctance machine (SRM) has been widely studied over the last decades. Due to inherent advantages such as high reliability, low cost and operation in harsh environment, SRM is a potential candidate for electric vehicles and hybrid electric vehicles applications. However, prevalent vibration and noise issues of SRM limit its use in the automotive industry, essentially because of the negative impact on the driver's and passengers' comfort. For these reasons, SRMs still require further efforts in order to reduce the acoustic noise and the vibration. It has been shown in [1] and [2] that the dominant source of the vibration and acoustic noise in the switched reluctance machine is the electromagnetic force between the stator and rotor poles. The interference between the vibrations generated via torque pulsation and the ones due to radial forces are also investigated by some researchers [3]-[5]. In the literature, two approaches have been investigated for vibration reduction: geometric optimization, generally used for the design of the mechanical part of the machine, and

Man Zhang, Imen Bahri, Xavier Mininger and Eric Berthelot are with Group of electrical engineering Paris (GeePs, UMR 8507) CNRS-CentraleSupélec -Université Paris-Sud-UPMC; 91192 Gif-Sur-Yvette, France. (e-mail: name@ geeps. centralesupelec.fr).

Cristina Vlad is with Laboratoire des Signaux et Systèmes (L2S, UMR CNRS 8506) CentraleSupélec-CNRS-Université Paris-Sud; Automatic Control Department, 91192 Gif-Sur-Yvette, France. (e-mail : cristina.vlad@ centralesupelec.fr)

This work is supported by CSC. (semi-active/active) control strategies that are able to limit the vibration independently of the design and sizing of phases. As it concerns the optimization-based design, several solutions have been proposed to improve vibration: skewing the rotor and stator to distribute the radial force [6], designing a cylindrical-shape rotor [7], investigating the effect of different shapes of stator and rotor poles on the maximum displacement of the stator [8], increasing the number of stator and rotor poles to reduce the radial force [9].

Among the control approaches, different strategies based on phase current profiling have been analyzed, such as nonsequentially excited half sine-wave currents [10] and two-stage [11] or three-stage [12] commutation methods, which proved to be able to reduce the vibration at the dominant natural frequency. Control methods that limit the change rate of the current [13]-[15] have also been studied. An alternative method is the semi-active/active control based on piezoelectric (PZT) actuators [16]-[19], where the number and the placement of actuators is optimized by genetic algorithms in order to reduce vibration. However, the semi-active/active control requires additional components - PZT.

In addition, several studies have been proposed to control the radial force directly. Moreover, researches in [20]-[24] point out that the variation of the radial force has a large impact on the vibratory performance. This point inspired the development of control methods aiming to smooth the total radial force, which is defined as the sum of the radial forces generated in the stator teeth. In [20], this objective is achieved by adopting the direct instantaneous force control (DIFC), along with a predictive controller used to compute the duty ratio of the PWM (Pulse-Width Modulation). However, this controller has the disadvantage of increasing the torque ripple. In [21], a control method named direct instantaneous torque and force control (DIT\&FC) is proposed. It aims to keep constant both overall torque and total radial force. However, the total losses have been increased up to $48 \%$ using this method, compared to the ones obtained with traditional current hysteresis control. In [22]-[24], the variation of the sum of radial forces has been minimized using a current profile control method. Yet, the methods are only suitable for three-phase SRM.

In this paper, a new control method is proposed, namely the direct force control with reference current adapter (DFC\&RCA) that is able to reduce the vibration of the SRM without increasing the torque ripple or decreasing the system efficiency. The structure of the paper is the following: the principle of the DFC\&RCA strategy is introduced in Section II. It consists of five parts: A) the torque ripple minimization 
control (TMC) using optimized control parameters $\left(I_{\text {ref }}{ }^{*}, \psi\right.$ and $\theta_{p}$ ) obtained by finite element method (FEM); B) the direct radial force control (DFC) aiming to obtain a smooth total radial force in order to improve the vibratory behavior; $\mathrm{C}$ ) the torque and radial force coupling, which aims to determine the relationship between the equivalent mean torque and equivalent mean radial force; D) the association of TMC and DFC and E) the reference current adapter (RCA) allowing a trade-off between torque ripple minimization and vibration reduction. In Section III, experimental results are provided using an 8/6 poles SRM. The DFC\&RCA is validated in different operating points.

\section{Control StRAtegy StRUCTURE AND DesigN}

The vibration reduction control strategy structure for the switched reluctance machine is presented in Fig. 1 . The torque reference $T_{\text {ref }}$ is computed by the speed controller. The IP (Integral-Proportional) control adopted for the speed loop to produce the reference torque $T_{\text {ref }}$ is not detailed in this paper. The main idea is to combine the TMC and the DFC, each controller being active depending on the level of torque ripple and vibration. Each part of the proposed control structure (A, B, $\mathrm{C}, \mathrm{D}$ and $\mathrm{E}$ shown in Fig. 1) is described in the following subsections.

\section{A. Torque Ripple Minimization Control (TMC)}

In the proposed control architecture, TMC is the fundamental control strategy that uses three optimal control parameters: the reference current $I_{r e f}{ }^{*}$, the turn on angle $\psi$ and the conduction angle $\theta_{p}$, whose definitions are presented in Fig. 2. The speed-dependent ranges for these three parameters are presented in [25]. Using the reference torque $T_{\text {ref }}$ and the actual speed $n$, the three control parameters are updated constantly using look-up tables (LUTs) containing the optimal values that assure a minimum torque ripple. These optimal values of the control parameters are obtained by FEM. The current loop (the “Current Controller" block in Fig. 1) uses a PWM-based PI controller. The TMC strategy and the corresponding results regarding torque ripple and vibrations have been largely described in [26]. The main drawback of the TMC approach is large vibration level. This means that the vibration aspect is not considered in the controller's design, since the shape of the radial forces is not controlled. The next part presents a

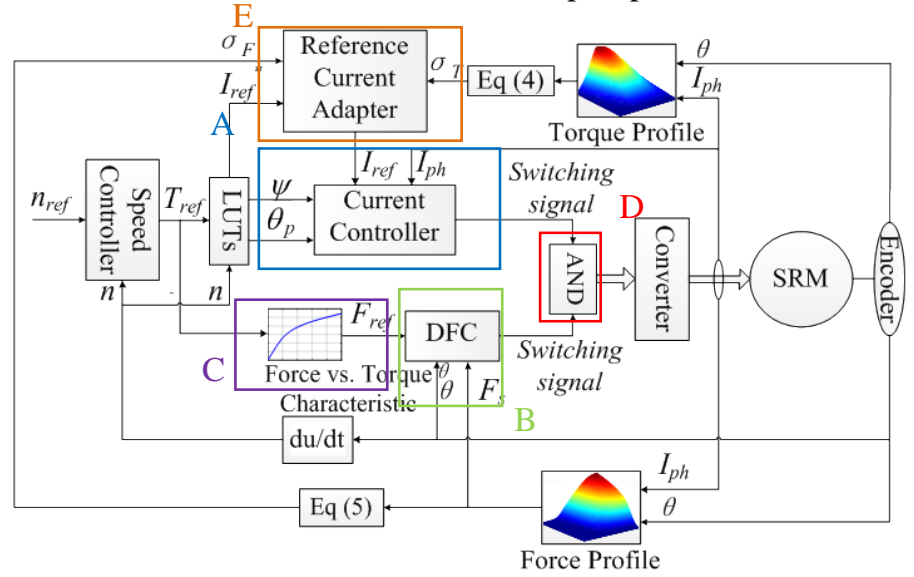

Fig. 1 Structure of the direct force control with reference current adapter (DFC\&RCA).

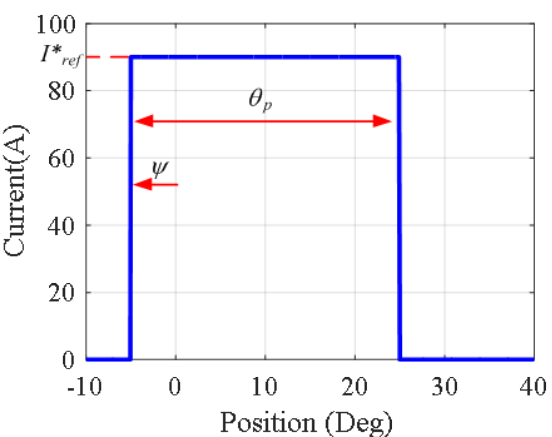

Fig. 2 Control parameters definition.

controller dedicated to this point and describes the coupling with the torque controller (TMC).

\section{B. Direct Force Control (DFC)}

The DFC is a control strategy based on direct instantaneous torque control (DITC), whose objective is to control the torque produced by each phase of the machine to get a total torque as constant as possible [27]. The aim of the adopted DFC is then to obtain a smooth total radial force by controlling the converter switches so that the sum of radial forces $F_{s}$, generated in the stator phases, reaches a desired value $F_{\text {ref }}$ at each moment, and then stays as constant as possible so as to limit the mechanical excitation. The control scheme of the SRM based on DFC is illustrated in Fig. 3.

The switching signals of the power converter are generated by the DFC block in order to reduce the difference between the desired total radial force $F_{\text {ref }}$ and the actual sum $F_{s}$ of radial forces of the phases. Due to its asymmetric half-bridge structure, the adopted converter can provide three different terminal voltages to the connected phase winding: positive, zero or negative.

Based on the same principle as the DITC [27], DFC consists of three hysteresis controllers that produce the switching signals for each phase of the SRM. The main difference with DITC is that the signal to be controlled is the total force instead of the total torque. Depending on the position of the rotor, the control process is divided into three regions under different control modes, as depicted in Fig. 4, and the switching rules of the hysteresis controllers for different modes are depicted in Fig. 5 . The hysteresis bands are defined within the interval $\left[-\Delta F^{*}\right.$, $\left.\Delta F^{*}\right], \Delta F^{*}$ being a control parameter that has to be defined.

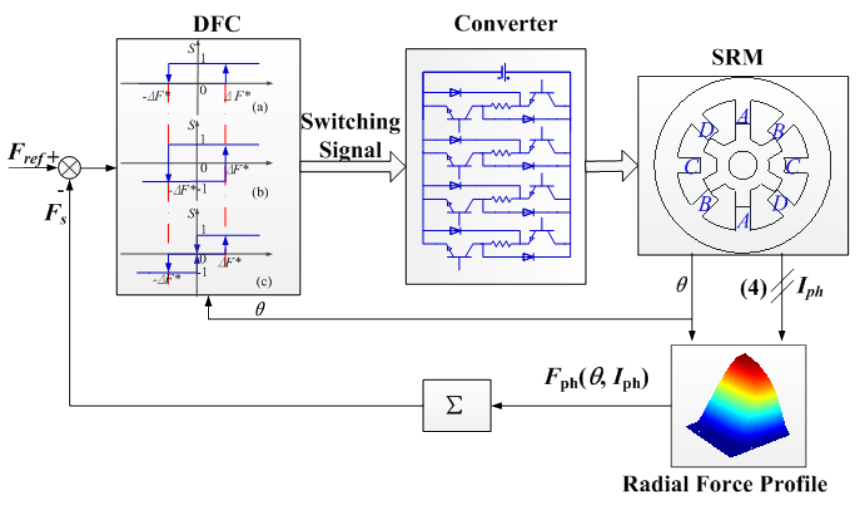


Fig. 3 Structure of direct force control.

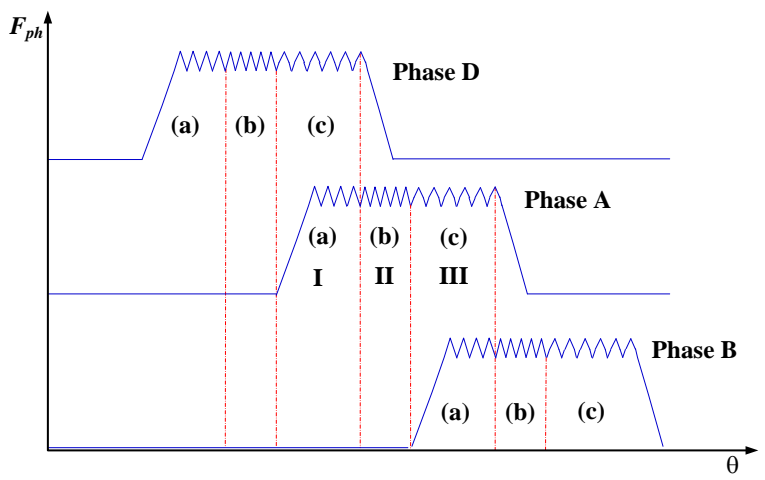

Fig. 4 Regions and control modes of the DFC.

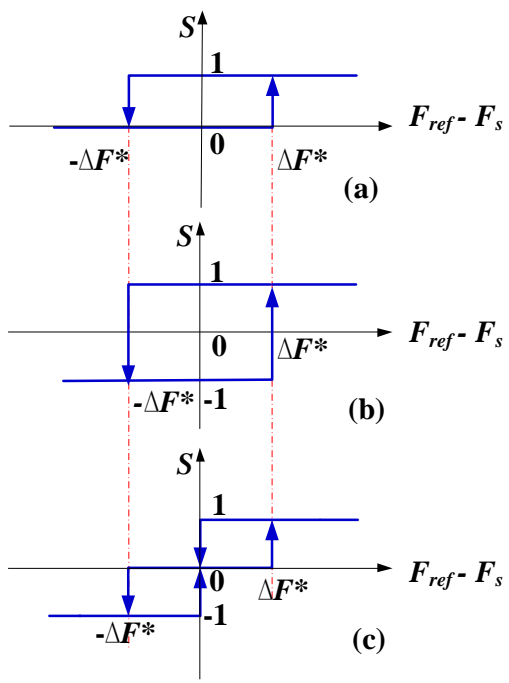

Fig. 5 Diagram of hysteresis controllers.

In part I, the A-phase force is smaller than the D-phase force, so the hysteresis (a) allows a limited switching rate. In part II, a high dynamic is required, which is obtained by hysteresis (b). In part III, since the A-phase force is high near aligned position, the hysteresis (c) allows a limited variation of the force around $F_{\text {ref. }}$ The detailed explanations of the DFC are introduced in [28].

\section{Coupling between Torque and Radial Force}

According to Fig. 1, the output of the speed controller is the torque reference required for the TMC implementation. In addition, DFC demands the reference value of the total radial force that should be generated to decrease vibration. However, as only one reference signal is provided by the speed controller of the machine, a relationship between reference torque and reference radial force is required. Thus, a static characteristic $F_{\text {ref }}=f\left(T_{\text {ref }}\right)$ is introduced, which allows to obtain the relationship between the equivalent mean radial force value and the equivalent mean torque value over one-half electrical period, as these two quantities are related. It is well-known that the torque and radial force profiles for the SRM present a highly nonlinear behavior that is related to the phase current and the rotor position (as shown in Fig. 6 and Fig. 7).

Based on these profiles, the equivalent mean values of both torque and radial force during one-half electrical period can be calculated, for each current. Actually, the mean values of these

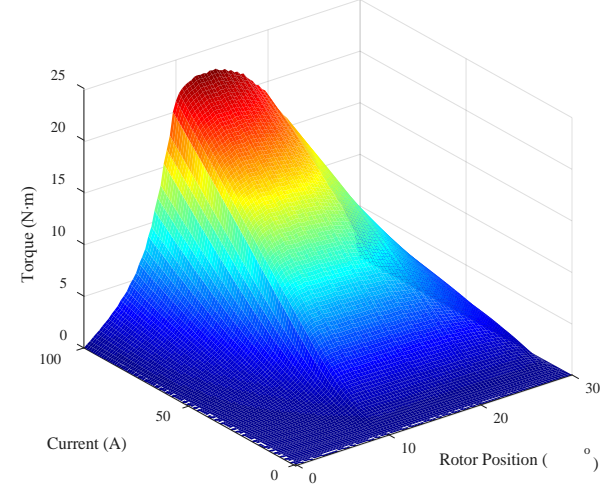

Fig. 6 Torque profile.

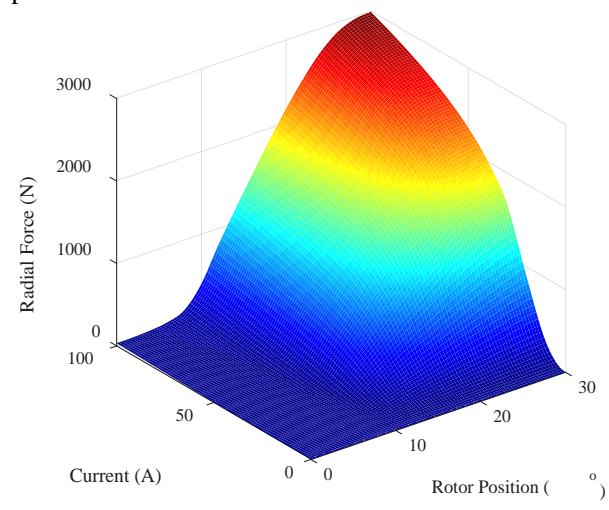

Fig. 7 Radial force profile.

quantities are dependent on the speed because the optimized parameters for the current reference depend on it. Since the force and torque are small near the unaligned position (rotor position equal to 0 ), we make the assumption that the integration can be done over the whole half period to get the mean value, instead of only over the conduction period. The considered expressions are then the following:

$$
\begin{aligned}
& T_{m}=\left.\frac{1}{\pi} \int_{0}^{\pi} T(I, \theta) d \theta\right|_{I=\text { const }} \\
& F_{m}=\left.\frac{1}{\pi} \int_{0}^{\pi} F(I, \theta) d \theta\right|_{I=\text { const }}
\end{aligned}
$$

Therefore, the relationship between the mean torque $T_{m}$ and mean radial force $F_{m}$ is obtained as illustrated in Fig. 8. Based on this static characteristic, the reference values of the torque and radial force are estimated simultaneously for different constant currents. 


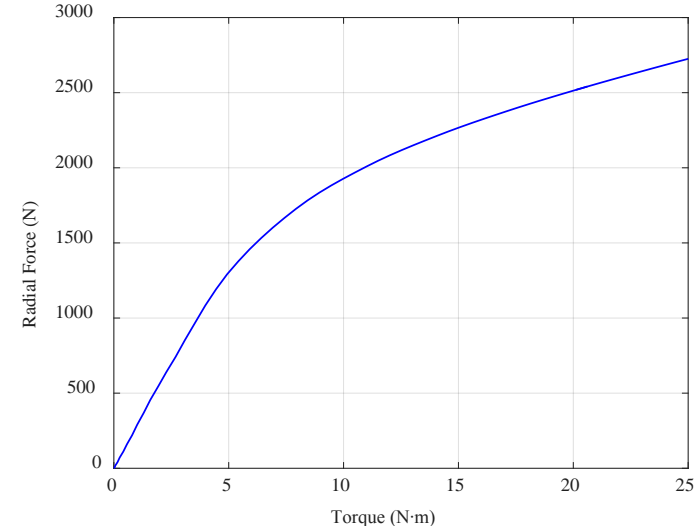

Fig. 8 Static characteristic between the mean total torque and the mean total radial force.

If only the DFC strategy is applied to the machine, the current amplitude will be modified to control the total radial force and to improve the vibratory behavior of the SRM. Nevertheless, the current amplitude will be different than the one obtained with TMC, since the current is not bounded anymore. Fig. 9 presents the simulation results to compare the accelerations of TMC and DFC in time and frequency domain. It can be seen that the DFC has a good performance in the vibration acceleration reduction. However, the torque ripple of DFC is five times the one obtained with TMC, which is caused by no current limitation as shown in Fig. 10 (c). The peak current of DFC is up to $91 \mathrm{~A}$, meanwhile, the TMC is only of 26 A. Due to the high amplitude of the phase current, a smooth total radial force is obtained in DFC, which reduces the vibration. However, it deteriorates the torque ripple, which may lead to secondary acoustic noise. Thus, the association of the TMC and the DFC is proposed in the following part, so that to benefit of both controllers' advantages.
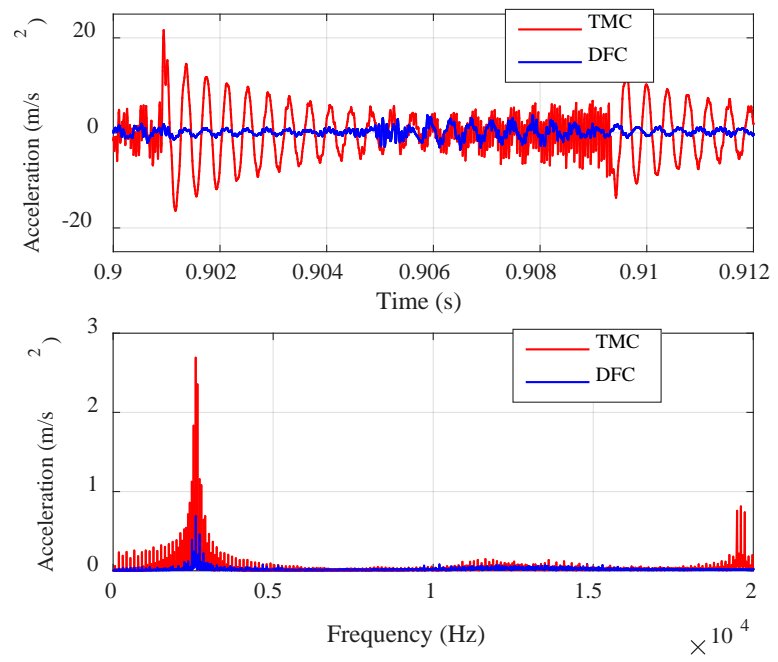

Fig. 9 Comparison between the TMC and the DFC: time-domain acceleration, frequency-domain acceleration at $n_{r e f}=600 \mathrm{r} / \mathrm{min}$ and $T_{L}=3 \mathrm{~N} \cdot \mathrm{m}$.
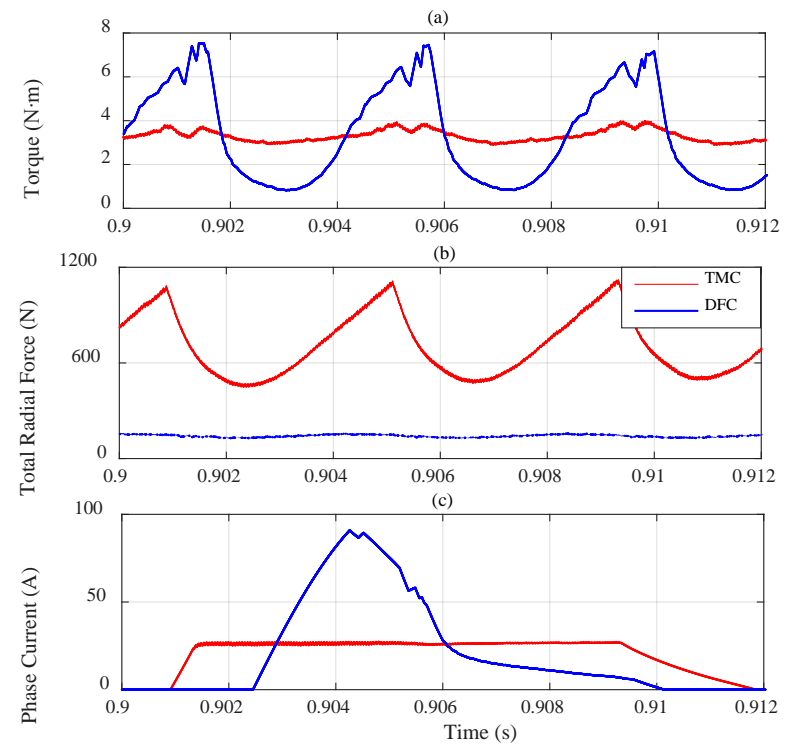

Fig. 10 Comparison between the TMC and the DFC: torque, total force and phase current at $n_{r e f}=600 \mathrm{r} / \mathrm{min}$ and $T_{L}=3 \mathrm{~N} \cdot \mathrm{m}$.

\section{Association of the TMC and the DFC}

As illustrated in Fig. 1, the association of the two controllers is simply a logical AND with the two switching signals as inputs. The idea is the following:

- While the total force does not reach the desired value $F_{\text {ref, }}$, only the output of the TMC is used for switching, and the DFC tries to impose 1 . As a consequence, the output of the AND block is similar to the output provided by the TMC.

- When the total radial force $F_{s}$ reaches $F_{\text {ref }}$, the DFC starts to impose switching signals in order to keep it to the desired value. Comparing to the case when the TMC is used alone, the main difference is the AND block output that equals 0 when the DFC tries to impose 0 and the TMC tries to impose 1 . Therefore, the resulting mean torque is slightly lower when the DFC is associated with the TMC.

Fig. 11 presents an example of waveforms obtained for the torque, the total forces and the switching signals send to the converter, using the association of the TMC and the DFC (simulation performed in MATLAB/Simulink).

As expected, when the force is small enough, the switching signals computed with the TMC+DFC and the TMC are similar. When the total force reaches $F_{\text {ref }}$, the impact of the DFC clearly appears (highlighted by the circle in Fig. 11). The total force is then controlled, and the torque is slightly decreased. Regarding vibrations, Fig. 12 shows the acceleration obtained in both cases, calculated with a SRM mechanical model based on the superposition of three $2^{\text {nd }}$ order transfer functions [29]. The mechanical model considered for this simulation is the analytical expression of the vibration associated to modes 0 ( $f_{0}$ $=11933 \mathrm{~Hz}), 2\left(f_{2}=2587 \mathrm{~Hz}\right)$ and $4\left(f_{4}=13721 \mathrm{~Hz}\right)$ of the considered SRM. It can be seen that the mode 2 is the dominant mode for the investigated SRM.

To assess the controllers' performances in a wide range of frequency, the total energy $W[26]$ is computed, because it gives a quantity related to the vibration behavior of all spectrum (all audible frequencies). The expression of the total energy $W$ is deduced from the energy spectral density as follows: 


$$
W=\int_{0}^{f_{\operatorname{mix}}} \alpha(f) a^{*}(f) d r
$$

where, $a(f)$ is the value of the acceleration FFT magnitude at the frequency $f, a^{*}(f)$ is the complex conjugate of $a(f)$ and $f_{\max }$ is the upper limitation of the considered frequency range. Using the association of the TMC and the DFC, a vibration energy reduction of $49.2 \%$ is obtained compared to using the TMC alone.

With such association, it is then possible to apply both TMC and DFC. The last element of the control architecture proposed in this paper is a reference current adapter that gives an additional parameter to control the trade-off between torque ripple and vibration.
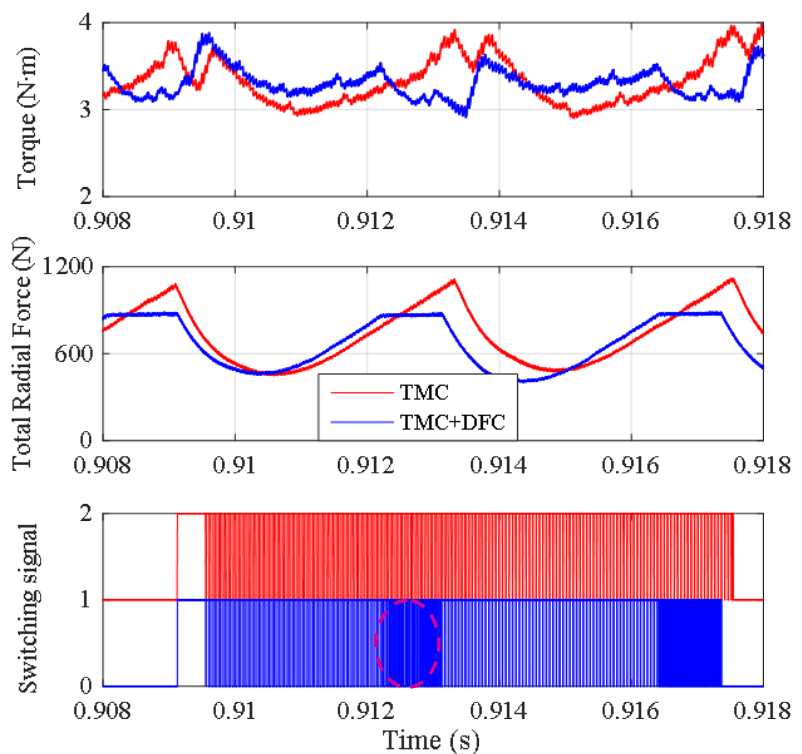

Fig. 11 Comparison between the TMC and the association TMC+DFC: torque, total radial force and switching signal at $n_{r e f}=600 \mathrm{r} / \mathrm{min}$ and $T_{L}=3 \mathrm{~N} \cdot \mathrm{m}$.
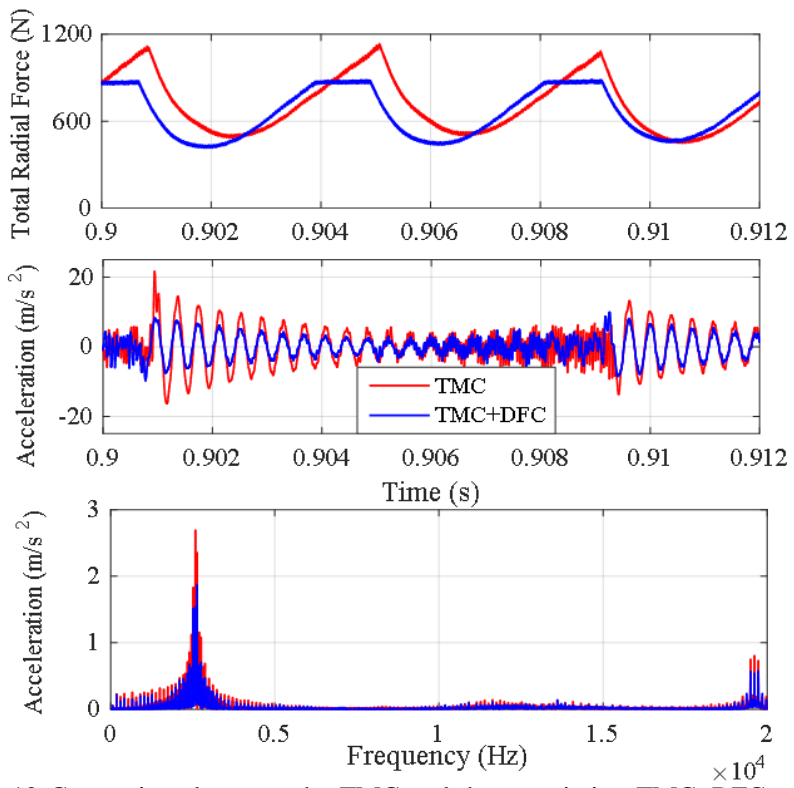

Fig. 12 Comparison between the TMC and the association TMC+DFC: total radial force, time-domain acceleration, frequency-domain acceleration at $n_{\text {ref }}=$ $600 \mathrm{r} / \mathrm{min}$ and $T_{L}=3 \mathrm{~N} \cdot \mathrm{m}$.

\section{E. Reference Current Adapter (RCA)}

The purpose of a reference current adapter is to manage the tradeoff between the two objectives (torque ripple minimization and vibration reduction) by updating the current reference. The value of the current reference is constantly adapted based on the variations of the total torque and radial forces within an electrical period, noted $\sigma_{T}$ and $\sigma_{F}$ respectively. These values are calculated using the following expressions:

$$
\begin{gathered}
\sigma_{T}=\sqrt{\int_{0}^{T_{c}}\left(T(t)-T_{\text {agg }}\right)^{2} d /\left(T_{\text {ag }}^{2} T_{c}\right)} \\
\sigma_{F}=\sqrt{\int_{0}^{T_{c}}\left(F(t)-F_{n f}\right)^{2} d /\left(F_{s}^{2} T_{c}\right)}
\end{gathered}
$$

where, $T(t), F(t)$ are the transient total torque and radial force, respectively; $T_{\text {avg }}, F_{\text {ref }}$ are the mean values of the total torque and the radial force reference during one electrical period, respectively; $T_{c}$ is the cycle time of one electrical period.

The structure of the reference current adapter is illustrated in Fig. 13. $I_{\text {ref }}[k]$ is the output of the reference current adapter at time instant $k . I_{\text {new }}[k]$ is the intermediate current reference value at time instant $k . \delta I$ is the current increment of the current adapter. $I_{r e f} *[k]$ is the reference current obtained from the optimized look-up table.

The details of the current adapter algorithm are presented in Fig. 14. $\varepsilon_{F}$ and $\varepsilon_{T}$ are upper limits for the variations of the total radial force and the total torque. The values of the parameters $\varepsilon_{F}$ and $\varepsilon_{T}$ are dependent on the SRM operating point as shown in Fig. 15. They have been determined by computing the torque variation $\sigma_{T}$ and the force variation $\sigma_{F}$ of TMC for different values of speed (range: [100, 3000] r/min) and torque (range: $[1,25] \mathrm{N} \cdot \mathrm{m}) . \Delta I$ is a constant value that can be tuned by the user: a too small value will slow down the current update, while a too big value will make the system unstable. In this paper, $\Delta I=0.5$, $\varepsilon_{F}=0.5$ and $\varepsilon_{T}=0.12$. The chosen values of $\varepsilon_{F}$ and $\varepsilon_{T}$ offer an acceptable trade-off between torque ripple minimization and vibration reduction for the considered SRM in the low speed region.

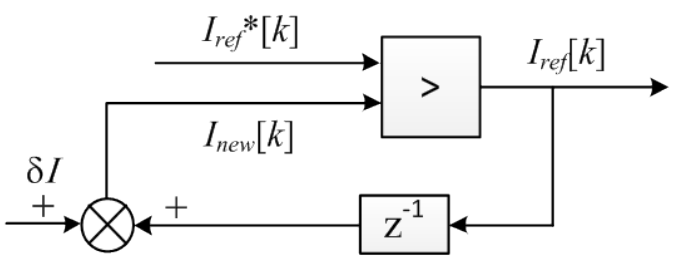

Fig. 13 Structure of the proposed reference current adapter. 


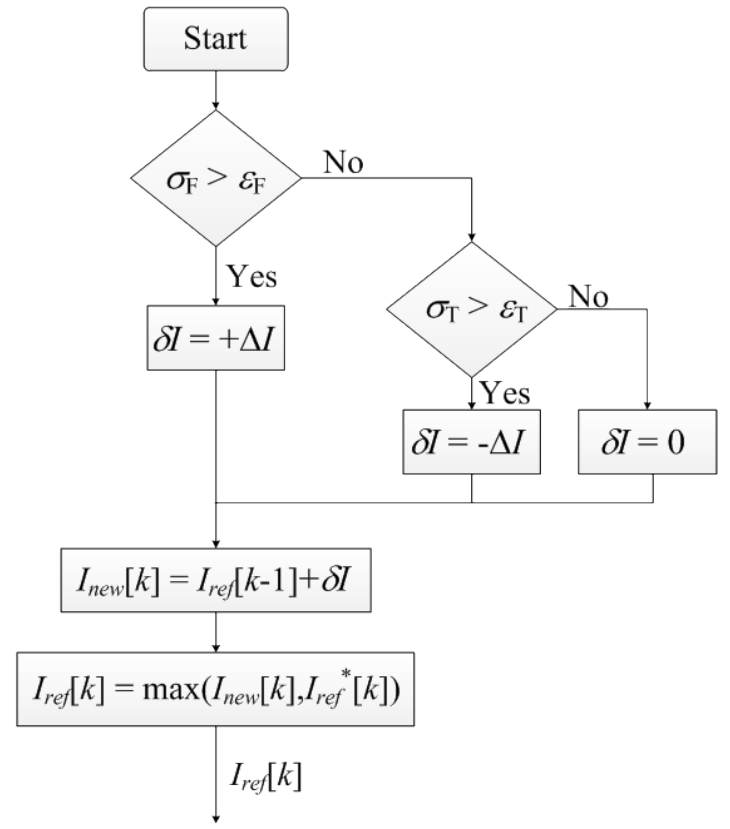

Fig. 14 Current adapter algorithm.

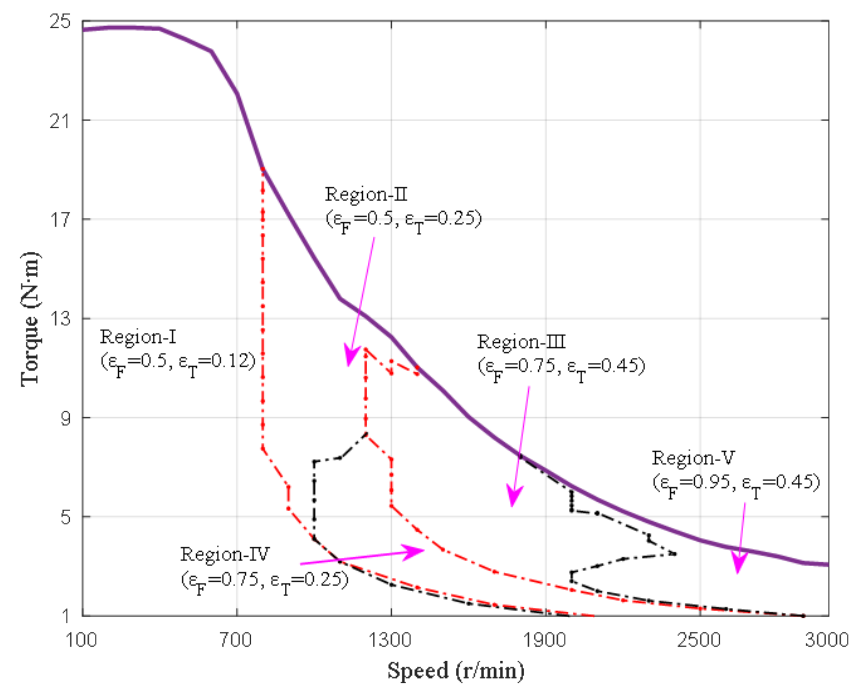

Fig. 15 Region division based on the torque variation bound $\varepsilon_{T}$ and the force variation bound $\varepsilon_{F}$.

The process of the current adaptor is as follows. Firstly, at each sampling instant, $\sigma_{T}$ and $\sigma_{F}$ are determined and compared to constants $\varepsilon_{T}$ and $\varepsilon_{F}$ in order to compute the intermediate current reference $I_{\text {new }}[k]$ and $I_{\text {ref }}[k]$. Since the main objective of this paper is to reduce the vibration, the force variation limitation $\varepsilon_{F}$ should be met at first. Actually, the condition $\sigma_{F}>$ $\varepsilon_{F}$ is satisfied when the total force is below the force reference. In this case, the current adapter will increase the reference current as long as the force variation $\sigma_{F}$ exceeds the limitation $\varepsilon_{F}$. If $\sigma_{F} \leq \varepsilon_{F}$ (i.e. the vibration criterion is validated), then the torque ripple criterion is considered. If $\sigma_{T}>\varepsilon_{T}$, that means that the torque has to be reduced to avoid a peak, so the reference current is reduced. If both variations of total torque and radial force are inside their allowed range, the intermediate current reference $I_{\text {new }}[k]$ is compared with the current reference signal $I_{\text {ref }} *[k]$. The reference current $I_{\text {ref }} *[k]$ is used to ensure the speed-up of the machine. Finally, the output of the reference current adapter is equal to the maximum between $I_{r e f} *[k]$ and $I_{\text {new }}[k]$. Thus, the RCA output is always superior or equal to $I_{\text {ref }}$ * to compensate the small decrease of the torque due to the association TMC+DFC.

Fig. 16 gives the comparison between $I_{\text {ref }}$ (LUTs output) and $I_{r e f}$ (RCA output). As shown in the figure, the reference current $I_{\text {ref }}$ increases at the beginning to reduce the force variation $\sigma_{F}$ and to meet the requirement of $\varepsilon_{F}$. When $\sigma_{F} \leq \varepsilon_{F}, I_{r e f}$ starts to decrease in order to reduce the torque ripple until $\sigma_{T}$ satisfies the requirement of $\varepsilon_{T}$. After the transient period, $I_{r e f}$ is slightly higher than $I_{r e f} *$.

Fig. 17 presents an example of waveforms obtained for the torque, total forces and switching signals send to the converter, using the TMC and the DFC\&RCA, respectively. It can be seen that when the DFC is associated to the RCA, it works in a wider region than in Fig. 11, which yields a higher reduction of the force variation. Fig. 18 shows the acceleration obtained with both controllers (the traditional TMC and the improved TMC, named DFC\&RCA). The vibration energy has been reduced up to $64.1 \%$ compared to the TMC.

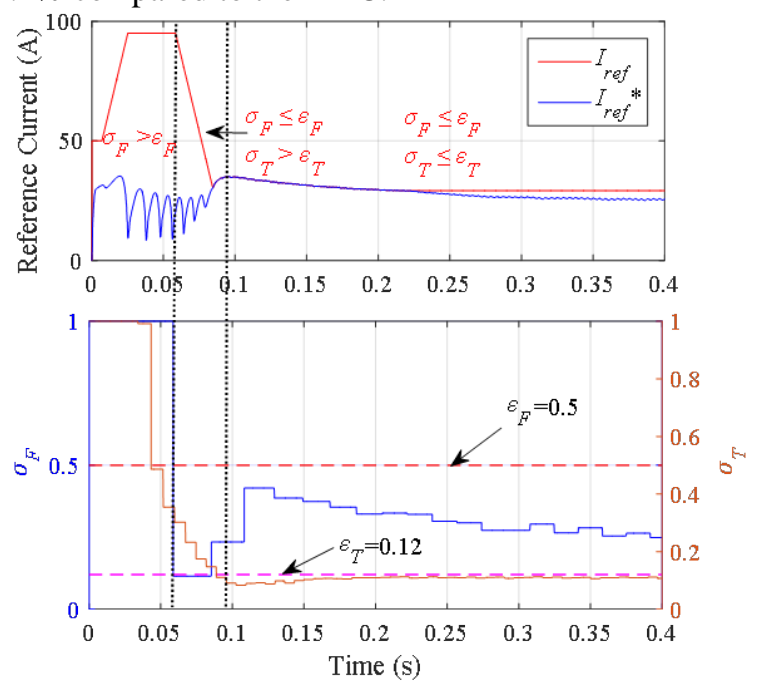

Fig. 16 Comparison between $I_{r e f}$ and $I_{r e f}$ * with the DFC\&RCA strategy at $n_{\text {ref }}=$ $600 \mathrm{r} / \mathrm{min}$ and $T_{L}=3 \mathrm{~N} \cdot \mathrm{m}$.

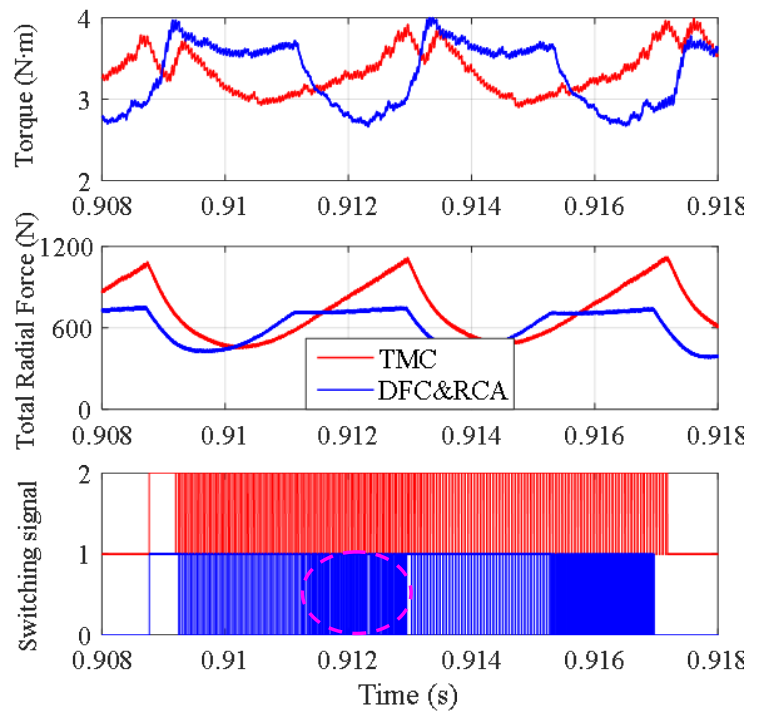

Fig. 17 Comparison between the TMC and the DFC\&RCA: torque, total forces and switching signal at $n_{\text {ref }}=600 \mathrm{r} / \mathrm{min}$ and $T_{L}=3 \mathrm{~N} \cdot \mathrm{m}$. 

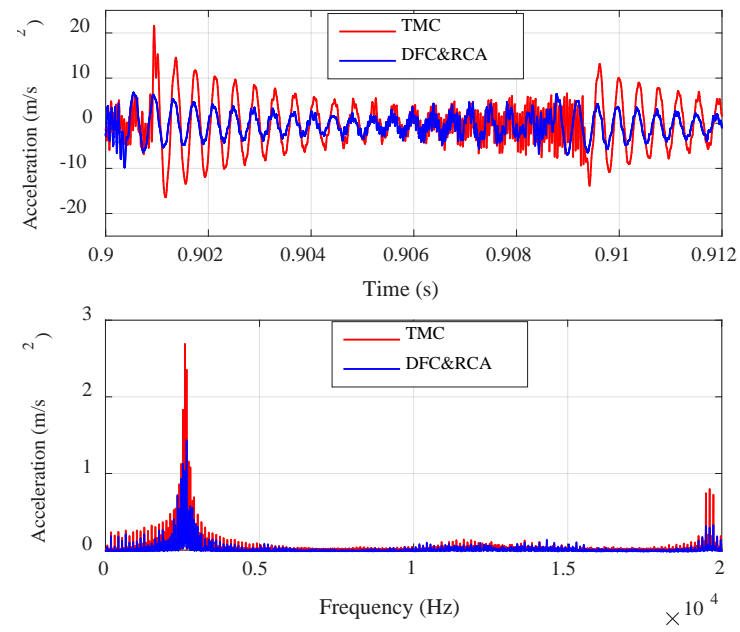

Fig. 18 Comparison between the TMC and the DFC\&RCA: time-domain acceleration, frequency-domain acceleration at $n_{r e f}=600 \mathrm{r} / \mathrm{min}$ and $T_{L}=3 \mathrm{~N} \cdot \mathrm{m}$.

In the next section, the proposed control structure is validated with an experimental bench, considering torque ripple, vibration and acoustic aspects.

\section{EXPERIMENTAL RESULTS}

The proposed control strategy (DFC\&RCA) is evaluated by experimental tests using an 8/6 SRM prototype (the parameters of the machine are given in TABLE I). The tests have been performed using dSPACE and FPGA control. The control system has been implemented as follows: the speed loop is executed in dSPACE; the current controller and the radial force controller are performed in FPGA due to its fast response and high calculation ability. The test bench is presented in Fig. 19 (for measurements, the microphone has been placed at $20 \mathrm{~cm}$ distance of the SRM). The drive system of the SRM is a FPGA-based control system. The DS5203 FPGA board is used. It features the Xilinx Virtex-5 FPGA running at $100 \mathrm{MHz}$, with 6 ADC and 16 digital I/O channels. The FPGA board is connected to the processor board of dSPACE via PHS (Physical High Speed) bus. A fiber optic cable connects the PC and the dSPACE board. An incremental encoder is mounted on the rotor shaft to detect the rotor position, with a resolution of $0.1^{\circ}$. The phase current is measured by the Hall-effect current sensor. Both signals (position and current measurements) are sent to the FPGA to be used for DFC and current control. The load of this machine is applied using the magnetic particle brake (MPB), which can be controlled via ControlDesk.

The experimental behavior of the closed-loop system is illustrated in Fig. 20 for a reference speed $n_{\text {ref }}$ of $600 \mathrm{r} / \mathrm{min}$ and a load torque $T_{\mathrm{L}}$ of $8 \mathrm{~N} \cdot \mathrm{m}$. According to the results from Fig. 20 (a), the current obtained with the DFC\&RCA has a higher peak value because of the DFC. However, the current in region (c) (introduced in Section II-B) is smaller than the one produced with the traditional control. Thus, the root mean square (RMS) value of the current is almost the same for both control strategies (TMC--30.5A; DFC\&RCA--30.8A). The estimated total radial force is given in Fig. 20 (b). The concave region obtained with the DFC\&RCA is caused by the current limitation used to reduce the torque ripple. The torque computed with the proposed control strategy and the TMC is presented in the Fig. 20(c). It should be noted that the mean torque is the same in both cases. Moreover, the measured efficiency of the drive system (including converter, SRM and power supply) is of $56.7 \%$ for each control method.

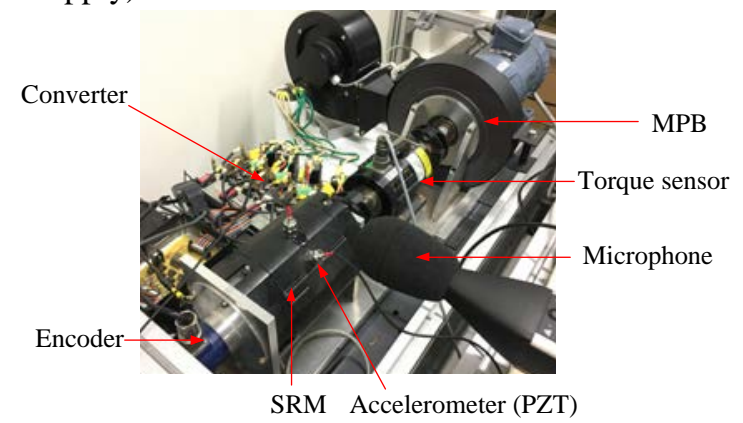

Fig. 19 Setup of the test bench.

TABLE I

ELECTRICAL PARAMETERS

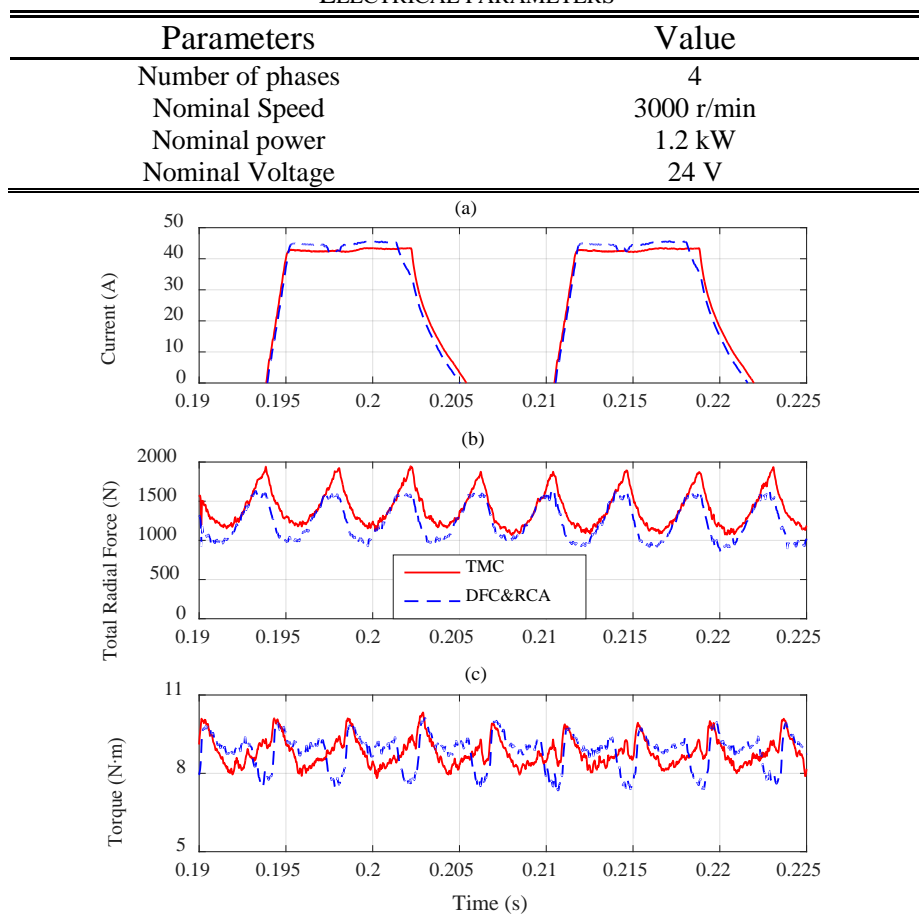

Fig. 20 Experimental results at $n_{r e f}=600 \mathrm{r} / \mathrm{min}$ and $T_{L}=8 \mathrm{~N} \cdot \mathrm{m}$.

Fig. 21 illustrates the SRM behavior for a reference speed $n_{\text {ref }}$ $=2000 \mathrm{r} / \mathrm{min}$ and load torque $T_{L}=0.6 \mathrm{~N} \cdot \mathrm{m}$. The peak value of the current is still bigger than the one generated by TMC. However, for both control approaches, the RMS values are identical (TMC--9.8 A; DFC\&RCA--9.8 A). The measured drive system efficiencies are both of $56.1 \%$. As presented in Fig. 21 (b), neither of the total radial forces are smooth. This is caused by two reasons. On one hand, it is attributed to the noise introduced to the phase current while the MOSFET is switching on and off. On the other hand, as the EMF increases with speed, the current changes rapidly when the state of the converter changes, which worsens the radial force variation. Even though the total radial force of the DFC\&RCA is not as smooth at high speed as at low speed (Fig. 20 (b)), its variation is still smaller compared with TMC. Thus, the vibration has been reduced as shown in Fig. 21 (c). This is attributed to the performance of 
DFC within the green-dashed circle (Fig. 21 (a)). It makes the phase current decrease faster than the TMC, which leads to a smaller radial force variation when the converter switches off at the turn-off position. Moreover, due to the small force variation assured by the hysteresis controllers of DFC, the vibratory behavior is also limited in that period.

Fig. 22 and Fig. 23 show the corresponding experimental results of the vibration acceleration spectrum. The acceleration data is acquired with the accelerometer (PZT) located over the A-phase tooth, in the middle of the axial lamination (see Fig. 19). The accelerometer is MMF KS76C IEPE (102.11 mV/g) with MMF M32 conditioner. The spectral analysis shows a significant vibration reduction. For a reference speed value of $600 \mathrm{r} / \mathrm{min}$ with a load torque of $8 \mathrm{~N} \cdot \mathrm{m}$, the maximum vibration value near its natural frequency has been reduced from 1.39 $\mathrm{m} / \mathrm{s}^{2}$ to $0.6 \mathrm{~m} / \mathrm{s}^{2}$ (reduction of 56.8\%). At the reference speed of $2000 \mathrm{r} / \mathrm{min}$, the maximum vibration value near its natural frequency is reduced from $2.56 \mathrm{~m} / \mathrm{s}^{2}$ to $1.49 \mathrm{~m} / \mathrm{s}^{2}$ (reduction of $41.8 \%)$.

The torque ripple is computed as follows:

$$
\gamma=100 \% *\left(T_{\max }-T_{\min }\right) / T_{\text {avg }}
$$

where $T_{\max }$ and $T_{\min }$ are respectively the maximum and minimum torque in one electrical period.

The total energy is decreased by $56.08 \%$ for a reference speed $n_{\text {ref }}$ of $600 \mathrm{r} / \mathrm{min}$ with a load of $8 \mathrm{~N} \cdot \mathrm{m}$. However, the torque ripple increases by $2.55 \%$. At a reference speed of 2000 $\mathrm{r} / \mathrm{min}$ with a load $0.6 \mathrm{~N} \cdot \mathrm{m}$, the total energy is decreased by $67.4 \%$ without increasing the torque ripple.

Fig. 24 and Fig. 25 show the spectrum of the sound pressure level. The acoustic noise has been reduced by $7.1 \mathrm{~dB}$ near the natural frequency for a reference speed of $600 \mathrm{r} / \mathrm{min}$ with a load of $8 \mathrm{~N} \cdot \mathrm{m}$, and a reduction of $4.3 \mathrm{~dB}$ is achieved near the natural frequency for the reference speed of $2000 \mathrm{r} / \mathrm{min}$ with a load of $0.6 \mathrm{~N} \cdot \mathrm{m}$.
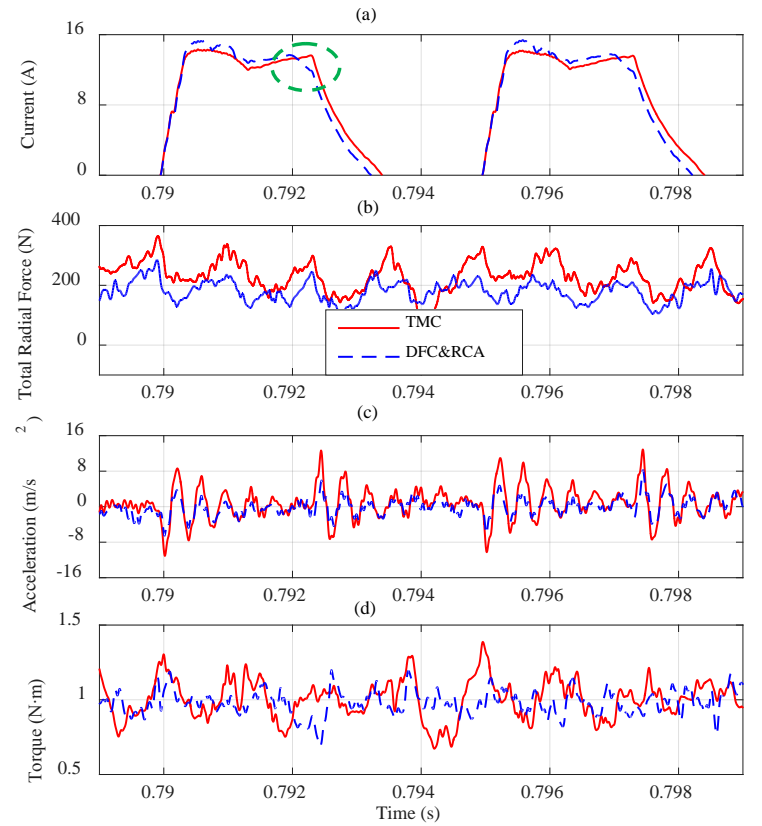

Fig. 21 Experimental results at $n_{r e f}=2000 \mathrm{r} / \mathrm{min}$ and $T_{L}=0.6 \mathrm{~N} \cdot \mathrm{m}$.
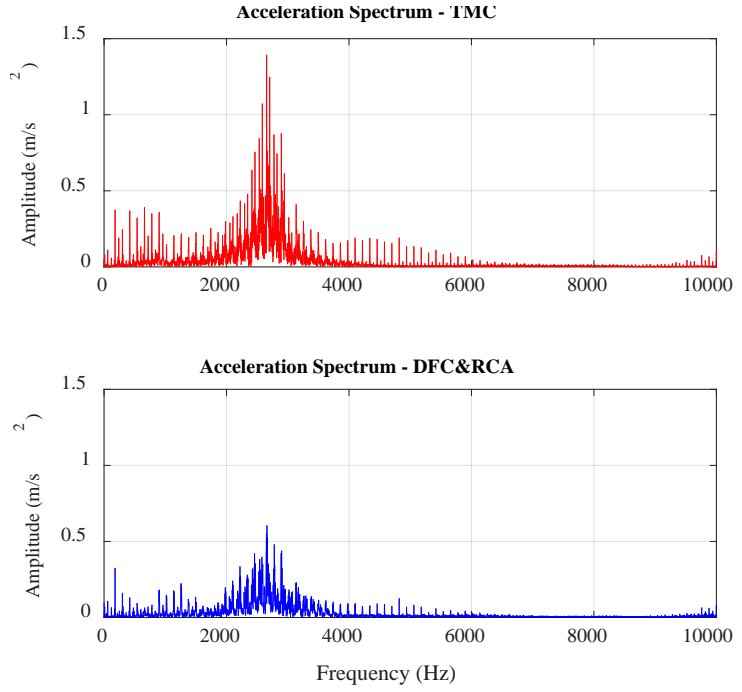

Fig. 22 Experimental results of vibration acceleration at $n_{\text {ref }}=600 \mathrm{r} / \mathrm{min}$ and $T_{L}$ $=8 \mathrm{~N} \cdot \mathrm{m}$.
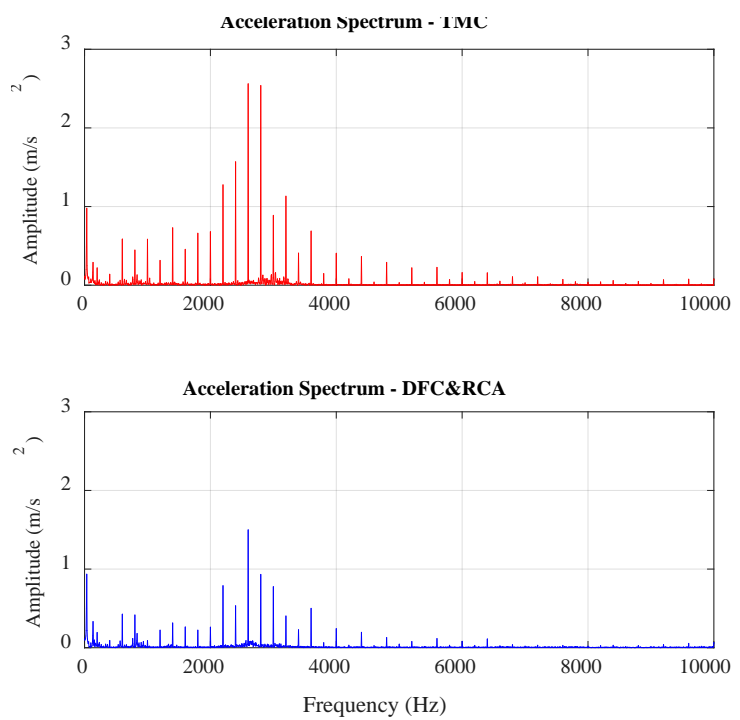

Fig. 23 Experimental results of vibration acceleration at $n_{\text {ref }}=2000 \mathrm{r} / \mathrm{min}$ and $T_{L}$ $=0.6 \mathrm{~N} \cdot \mathrm{m}$.
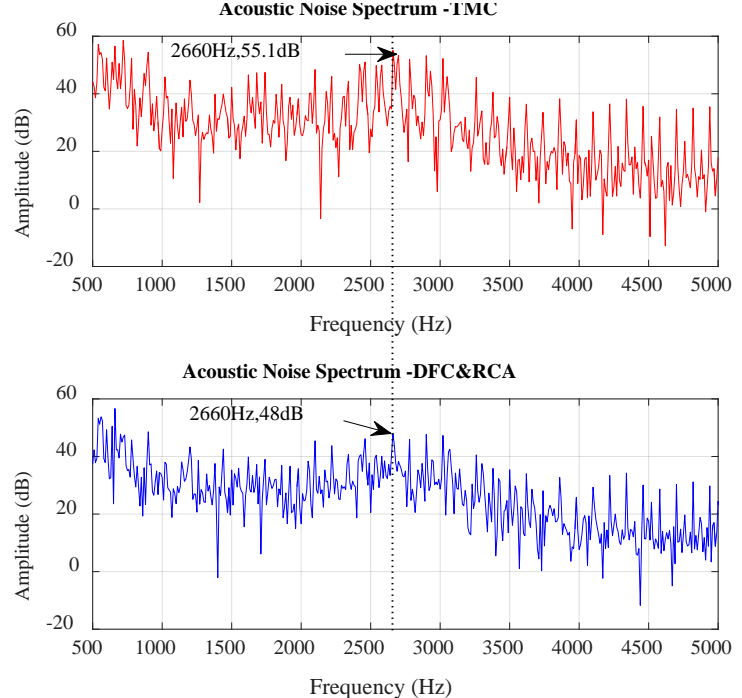

Fig. 24 Experimental results of acoustic noise at $n_{r e f}=600 \mathrm{r} / \mathrm{min}$ and $T_{L}=8 \mathrm{~N}$. $\mathrm{m}$. 

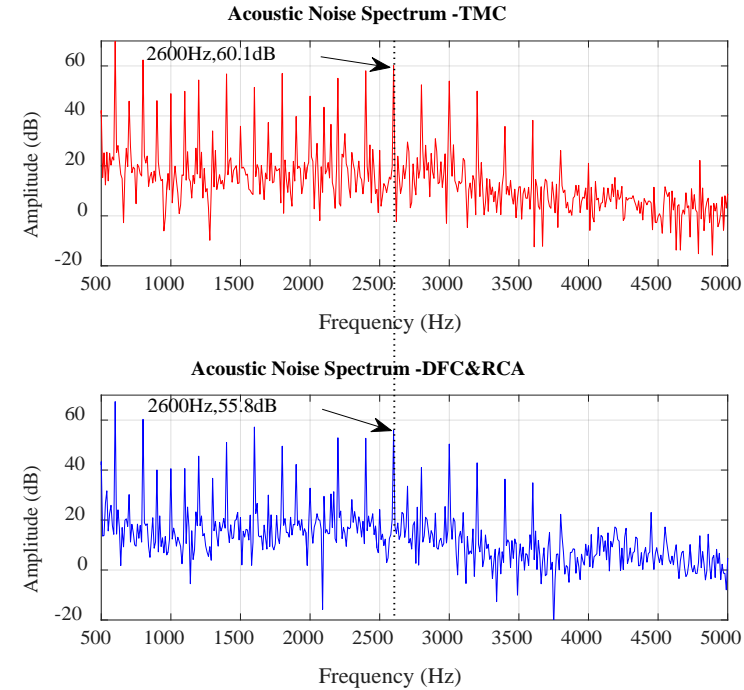

Fig. 25 Experimental results of acoustic noise at $n_{\text {ref }}=2000 \mathrm{r} / \mathrm{min}$ and $T_{L}=0.6$ $\mathrm{N} \cdot \mathrm{m}$.

Furthermore, the performances of the proposed control strategy have been evaluated for different speeds with a load torque of $2 \mathrm{~N} \cdot \mathrm{m}$ and for different loads with the reference speed $600 \mathrm{r} / \mathrm{min}$. The vibration energy and torque ripple, respectively, are shown in TABLE II and TABLE III. According to the results, the DFC\&RCA energy reduction percentage is above $35 \%$ with a maximum torque ripple increase of $6.07 \%$. Moreover, the efficiency for the two control methods are the same for all the considered operating points.

TABLE II

PERFORMANCE COMPARISON AT CONSTANT LOAD TORQUE $\mathrm{T}_{\mathrm{L}}=2 \mathrm{~N} \cdot \mathrm{M}$

\begin{tabular}{ccc}
\hline \hline Reference Speed & $\begin{array}{c}\text { Vibration Energy } \\
\text { Reduction }\end{array}$ & Ripple Increase \\
\hline$n_{\text {ref }}=200 \mathrm{r} / \mathrm{min}$ & $36.93 \%$ & $6.07 \%$ \\
$n_{\text {ref }}=400 \mathrm{r} / \mathrm{min}$ & $35.21 \%$ & $4.52 \%$ \\
$n_{\text {ref }}=600 \mathrm{r} / \mathrm{min}$ & $54.22 \%$ & $3.54 \%$ \\
$n_{\text {ref }}=800 \mathrm{r} / \mathrm{min}$ & $47.44 \%$ & $5.4 \%$ \\
\hline \hline
\end{tabular}

TABLE III

PERFORMANCE COMPARISON AT CONSTANT REFERENCE SPEED N $\mathrm{N}_{\text {REF }}=600 \mathrm{R} / \mathrm{MIN}$

\begin{tabular}{ccc}
\hline \hline Load Torque & $\begin{array}{c}\text { Vibration Energy } \\
\text { Reduction }\end{array}$ & Ripple Increase \\
\hline$T_{L}=2 \mathrm{~N} \cdot \mathrm{m}$ & $54.22 \%$ & $3.54 \%$ \\
$T_{L}=4 \mathrm{~N} \cdot \mathrm{m}$ & $54.81 \%$ & $2.89 \%$ \\
$T_{L}=6 \mathrm{~N} \cdot \mathrm{m}$ & $53.82 \%$ & $4.81 \%$ \\
$T_{L}=8 \mathrm{~N} \cdot \mathrm{m}$ & $56.08 \%$ & $2.55 \%$ \\
\hline \hline
\end{tabular}

\section{CONCLUSION}

A new control method is proposed to handle the torque ripple and the vibration that are common issues for the switch reluctance machines. The DFC method is presented as a solution for the vibration reduction aiming to provide a smooth sum of radial forces. However, the DFC cannot be used alone because it increases the torque ripple. To handle the trade-off between the torque ripple minimization and the vibration reduction, a reference current adapter is designed to assess the torque and radial force variations in order to obtain an auto-tuning current reference. Finally, experimental results of the proposed control method are compared with the traditional TMC, showing that the vibration energy can be reduced up to $67.4 \%$ without penalizing the torque ripple, which proves the potential of the proposed DFC\&RCA strategy. The maximum reduction of the sound pressure level near the natural frequency is of $7.1 \mathrm{~dB}$ that confirms further the effectiveness of the proposed control method. The accurate determination of the radial force characteristic is the future work since it has been the bottleneck of the DFC implementations.

\section{REFERENCES}

[1] M. N. Anwar, and I. Husain. "Radial force calculation and acoustic noise prediction in switched reluctance machines." IEEE Trans. Ind. Appl., vol. 36, no. 6, pp. 1589-1597, Nov/Dec 2000.

[2] M. N. Anwar, I. Husain, S. Mir and T. Sebastian. "Evaluation of acoustic noise and mode frequencies with design variations of switched reluctance machines." IEEE Trans. Ind. Appl., vol. 39, no. 3, pp. 695-703, May/Jun 2003.

[3] T. Kojima, R W. De Doncker, "Optimal torque sharing in direct instantaneous torque control of switched reluctance motors," in Proc. ECCE 2015, pp. 327-333.

[4] C. Ma, L. Qu, R. Mitra, P. Pramod, and R. Islam, "Vibration and torque ripple reduction of switched reluctance motors through current profile optimization," in Proc. APEC 2016, pp. 3279-3285.

[5] C. Gan, J. Wu, Q. Sun, W. Kong, H. Li, and Y. Hu, “A Review on Machine Topologies and Control Techniques for Low-Noise Switched Reluctance Motors in Electric Vehicle Applications," IEEE Access 2018.

[6] C. Gan, J. Wu, M. Shen, S. Yang, Y. Hu, and W. Cao, "Investigation of skewing effects on the vibration reduction of three-phase switched reluctance motors,” IEEE Trans. Magn., vol. 51, no. 9, pp. 1-9, Sep. 2015.

[7] K. Kiyota, T. Kakishima, A.Chiba and M.A. Rahman, "Cylindrical Rotor Design for Acoustic Noise and Windage Loss Reduction in Switched Reluctance Motor for HEV Applications," IEEE Trans. Ind. Appl., vol. 52, no. 1, pp. 154-162, Jan./Feb. 2016.

[8] K. Edamura and I. Miki, "Design of stator and rotor for noise reduction of SRM," in Proc. ICEMS 2014. pp. 1871-1874.

[9] T. Kakishima, K. Kiyota, S. Nakano, and A.Chiba. "Pole selection and vibration reduction of Switched Reluctance Motor for hybrid electric vehicles”. in Proc. ITEC, 2014. pp. 1-4.

[10] N. Nakao, K. Akatsu, "A Simple Unipolar Excitation Strategy for Switched Reluctance Motors by Using PWM Current Control," in Proc. ECCE Asia 2013, pp. 1111-1117.

[11] H. Makino, T. Kosaka, and N. Matsui, "Digital PWM-Control-Based Active Vibration Cancellation for Switched Reluctance Motors” IEEE Trans Ind. Appl., vol. 51, no. 6, pp. 4521-4530, Nov/Dec 2015.

[12] C. Pollock, C. Y. Wu, "Acoustic noise cancellation techniques for switched reluctance drives,” IEEE Trans. Ind. Appl., vol. 33, no. 2, pp. 477-484, Mar/Apr 1997.

[13] T. Boukhobza, M. Gabsi, and B. Grioni, "Random variation of control angles, reduction of SRM vibrations," in Proc. IEMDC 2001, pp. 640-643.

[14] J. Y. Chai, Y. W. Lin and C. M. Liaw. "Comparative study of switching controls in acoustic noise and vibration reductions for switched reluctance motor," IET Electr. Power Appl., vol. 153, no. 3, pp. 348-360, May 2006.

[15] J. W. Ahn, S. J. Park, and D. H. Lee, "Hybrid excitation of SRM for reduction of vibration and acoustic noise," IEEE Trans. Ind. Electron., vol. 51, no. 2, pp. 374-380, Apr 2004.

[16] X. Ojeda, M. Gabsi, M. Lecrivain, and X. Mininger, "Noise reduction using piezoelectric active control on high speeds switched reluctance drives,” Conf. Rec. IEEE-IAS Annu. Meeting, 2007, pp. 2204-2209.

[17] X. Mininger, E. Lefeuvre, M. Gabsi, C. Richard and D. Guyomar, "Semiactive and active piezoelectric vibration controls for switched reluctance machine," IEEE Trans. Energy. Convers., vol. 23, no. 1, pp. 78-85, Mar 2008.

[18] X. Ojeda, X. Mininger, M. Gabsi, C. Kulcsar, H. F. Raynaud, and M. Lecrivain, "Design of controllers: Vibration damping of switched reluctance machine by piezoelectric actuators," in Proc. ELECTROMOTION 2009, pp. 1-6.

[19] X. Ojeda, X. Mininger, M. Gabsi, and M. Lecrivain, "Noise cancellation of 6/4 switched reluctance machine by piezoelectric actuators: Optimal 
design and placement using genetic algorithm," in Proc. PEMD 2008, pp. 611-615.

[20] A. Hofmann, A. Al-Dajani, M. Bösing, and R. W. De Doncker, "Direct instantaneous force control: A method to eliminate mode-0-borne noise in switched reluctance machines," in Proc. IEMDC 2013, pp. 1009-1016.

[21] K.H. Annegret, A. Hofmann, and R. W. De Doncker. "Direct instantaneous torque and force control: a control approach for switched reluctance machines." Electr. Power, vol. 11, no. 5, pp. 935-943, Appl., 2017

[22] M. Takiguchi, H. Sugimoto, N. Kurihara, A. Chiba, "Acoustic noise and vibration reduction of SRM by elimination of third harmonic component in sum of radial forces," IEEE Trans. Energy. Convers., vol. 30, no. 3, pp. 883-891, Sept 2015.

[23] N. Kurihara, J. Bayless, and A. Chiba, "Noise and vibration reduction of switched reluctance motor with novel simplified current waveform to reduce force sum variation,” in Proc. IEMDC 2015, pp. 1794-1800.

[24] J. Bayless, N. Kurihara, H. Sugimoto, and A. Chiba, "Acoustic noise reduction of switched reluctance motor with reduced RMS current and enhanced efficiency," IEEE Trans. Energy. Convers., vol.31, no.2, pp. 627-636, June 2016.

[25] Hannoun H, Hilairet M, Marchand C. Design of an SRM speed control strategy for a wide range of operating speeds. IEEE Trans. Ind. Electron., vol. 57, no. 9, pp. 2911-2921, Sept 2010.

[26] A. Kolli, G. Krebs, X. Mininger, and C. Marchand, "Impact of command parameters on efficiency, torque ripple and vibrations for switched reluctance motor,” ICEM 2012, pp. 2975-2980.

[27] R. B. Inderka, R. W. De Doncker, "A. DITC-direct instantaneous torque control of switched reluctance drives," IEEE Trans. Ind. Appl., vol. 39, no. 4, pp. 1046-1051, Jul 2003.

[28] M. Zhang, I. Bahri, X. Mininger, and C. Vlad, "A new vibration reduction control strategy of switched reluctance machine,” in Proc. IEMDC 2017, pp.1-6.

[29] M. Zhang, X. Mininger, I. Bahri and C. Vlad. "Improvement of the variable turn-off angle control for SRM regarding vibration reduction," in Proc. IEMDC2017, pp. 1-7. 